\title{
CALPHAD-Based Modeling and Experimental Validation of Microstructural Evolution and Microsegregation in Magnesium Alloys During Solidification
}

\author{
Chuan Zhang ${ }^{1} \cdot{\text { Jiashi } \mathrm{Miao}^{2} \cdot \text { Shuanglin Chen }}^{1} \cdot$ Fan Zhang $^{1} \cdot$ Alan A. Luo ${ }^{2}$
}

Submitted: 11 December 2018/in revised form: 8 April 2019/Published online: 16 May 2019

(C) ASM International 2019

\begin{abstract}
The microstructural evolution and microsegregation of a series of magnesium alloys ( $\mathrm{Mg}-\mathrm{Al}, \mathrm{Mg}-\mathrm{Al}-\mathrm{Ca}$ and $\mathrm{Mg}-\mathrm{Al}-\mathrm{Sn}$ ) at various cooling rates were investigated using a CALPHAD-based solidification model called PanSolidification. Experimental validations were carried out in a wide range of cooling rate $(0.12 \sim 55 \mathrm{~K} / \mathrm{s})$ using both directional solidification and die casting techniques. The back-diffusion effect in solidified solid was included in the solidification model. Good agreements have been achieved between the simulated and measured solidification microstructure parameters (phase fraction and secondary dendrite arm spacing) and microsegregation within the $\alpha(\mathrm{Mg})$ phase. This modeling approach demonstrated the reliability of the CALPHAD-based models for the prediction of solidification microstructure of magnesium alloys and their applicability for the optimization of magnesium castings.
\end{abstract}

Keywords back diffusion in solidification - CALPHAD (CALculation of PHAse Diagram) - microstructure simulation $\cdot$ solidification modeling

This article is an invited paper selected from presentations at "PSDK XIII: Phase Stability and Diffusion Kinetics," held during MS\&T'18, October 14-18, 2018, in Columbus, Ohio. The special sessions were dedicated to honor Dr. John Morral, recipient of the ASM International 2018 J. Willard Gibbs Phase Equilibria Award "for fundamental and applied research on topology of phase diagrams and theory of phase equilibria resulting in major advances in the calculation and interpretation of phase equilibria and diffusion." It has been expanded from the original presentation.

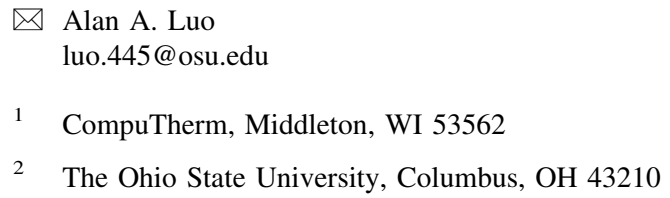

2 The Ohio State University, Columbus, $\mathrm{OH} 43210$

\section{Introduction}

Reducing vehicle weight is an important approach for increasing fuel economy and reducing emission of greenhouse gases. Magnesium ( $\mathrm{Mg}$ ) alloys are among the lightest structural metals and offer significant weight saving potential. The vast majority of $\mathrm{Mg}$ applications in vehicles $(>90 \%)$ are high pressure die casting, which affords tremendous design flexibility and opportunities for part integration, thereby lowering "system" cost. ${ }^{[1-3]}$ One challenge that $\mathrm{Mg}$ alloys face in actual applications has been to modify alloy chemistry/microstructure to ensure good castability, high mechanical properties, and reasonable resistance to creep and corrosion. ${ }^{[4]}$ These properties of cast $\mathrm{Mg}$ alloys are generally attributed to several microstructural parameters, such as grain size, primary dendrite arm spacing (PDAS), secondary dendrite arm spacing (SDAS), microsegregation of alloying elements, distribution/fractions of constituent phases, etc. ${ }^{[5]}$ Therefore, it is essential to comprehend the correlation between as-cast microstructure and casting process conditions in order to obtain the tailored microstructure. The future of material design and development will be based on a holistic $\mathrm{ICME}^{[6]}$ (Integrated Computational Materials Engineering) approach $^{[7]}$ and the goal of this research is to predict microsegregation as a part of microstructure modeling in the ICME framework for $\mathrm{Mg}$ castings.

Casting is a solidification process of liquid material in a mold, and the science and engineering of solidification mechanisms have been well documented in several textbooks such as the ones by Flemings ${ }^{[8]}$ as well as Kurz and Fisher. ${ }^{[9]}$ Solidification processes are modeled and described in terms of thermodynamics, kinetics, heat transfer, fluid flow, stress analysis, defect formation, microstructure evolution, and thermophysical and mechanical 
properties. $^{[10]}$ The solidification behavior of an alloy is determined by its solidification path, which describes the phase formation sequence during solidification. Therefore, it is critical to obtain an accurate solidification path for understanding and controlling the solidification process of the alloy. ${ }^{[11]}$ Phase diagrams are frequently used to understand the solidification path of an alloy cooled from the liquid state to room temperature. For multicomponent industrial alloys, their solidification paths are very complex. Based on CALPHAD (CALculation of PHAse Diagram) principles, ${ }^{[11-14]}$ the solidification path of an alloy can be calculated using two approximate models, equilibrium (lever-rule) and non-equilibrium (Scheil-Gulliver) models, ${ }^{[15,16]}$ in a simple and efficient way without evoking complex kinetic calculations. These two models both assume complete mixing in the liquid. In the solid, the lever-rule model assumes the solute diffusivity is infinity, while the Scheil model assumes that the solute diffusion in the solid phase is small enough to be negligible. As one can see, these two models describe the two extreme cases. While in almost all practical situations, the solidification occurs under non-equilibrium conditions but does not follow either of the two models. There is usually finite diffusion in the solid, the so-called "back-diffusion", which is a function of cooling rate and plays an important role in the alloying element segregation as well as the final as-cast microstructure. Thus, the solute back diffusion within the solid under different cooling conditions needs to be considered in order to accurately predict the solidification processes. ${ }^{[17]}$ Here, it should be noted that the CALPHAD approach $^{[11-14]}$ is currently the only method that can be used to obtain multi-component phase diagrams with enough accuracy for practical applications without the need of exhaustive experimental work. ${ }^{[18]}$ Several application examples have suggested that CALPHAD method is a key building block in the ICME framework for casting design and development. ${ }^{[6]}$

There are many numerical and analytical models that attempt to handle the microsegregation phenomena during casting processes. ${ }^{[19-32]}$ The level of complexity of these micromodels varies considerably, but all require phase diagram information, such as the compositions of the liquid and solid phases at the liquid/solid interface or the partition coefficients. However, the partition coefficients, as a function of temperature and composition of alloying elements, are usually unknown for multicomponent systems. Common practices when dealing with a multicomponent system include simplifying it as a binary or ternary system, using linearized partition coefficients estimated from binary systems, and treating these coefficients as constants. These practices can lead to serious errors in the simulation results. Multicomponent phase diagrams are therefore essential in obtaining accurate partition coefficients of a multicomponent system. On the other hand, the predictions of a micromodel are strongly affected by the shape of the local cooling curves. At high cooling rates, solute trapping and other effects offset the local equilibrium at the $S / L$ interface, and undercooling phenomena need to be considered. Additionally, dendrite coarsening also contributes significantly to homogenization during solidification, due to the re-melting and re-solidification mechanisms of such dendrites. In order to predict microstructure and microsegregation as a function of alloy chemistry and process variables, microscopic modeling should take into account all thermodynamics and kinetics of the material system.

As one of the pioneering work in the field of microstructure and microsegregation during dendritic solidification, Kraft et al. ${ }^{[33,34]}$ developed an extensive micromodel considering all kinetic and thermodynamic effects that can influence microsegregation, such as solid state back diffusion, secondary dendritic arm coarsening, primary tip, eutectic undercooling, and the thermodynamic correction of the interface concentrations. In 1997, Kraft and Chang ${ }^{[35]}$ gave a comprehensive overview of analytical approaches as well as advanced numerical models for predicting microstructure and microsegregation in multicomponent alloys in the past few decades and pointed out that the accuracy of multicomponent phase diagram is crucial for reliable microsegregation predictions. By coupling the micromodel of Kraft et al. ${ }^{[33,34]}$ with CALPHAD calculated compositions of liquid and solid phases in equilibrium, the microstructure and microsegregation in Al-rich Al-Cu-Mg ternary alloys were simulated by Xie et al. ${ }^{[36]}$ in the group of Y.A. Chang in Madison. The model-calculated results were found to be in good agreement with the experimentally determined concentration distributions in the primary $(\mathrm{Al})$ phase and the amounts of phases formed. Although the micromodel hasn't been seamlessly coupled with the CALPHAD approach in this work, it opened up a new direction to couple the micromodel with CALPHAD approach for the simulation of microstructure and microsegregation during solidification. As a continuous and extended work, Yan, ${ }^{[37]}$ from the same group of Chang directly coupled the model of Kraft et al., ${ }^{[33,34]}$ with multicomponent phase diagram calculations and successfully applied to predict the microstructure and microsegregation of multicomponent Al-rich alloys, such as Al-Cu-Mg-Si and Al-Cu-Mg-Zn quaternary alloys.

Based on the previous work of Yan, ${ }^{[37]}$ the PanSolidification module of Pandat ${ }^{\mathrm{TM}}$ software ${ }^{[38,39]}$ is developed by coupling a solidification micro-model with PanEngine. ${ }^{[38]}$ This micro-model is the models from Kraft et al., ${ }^{[33,34]}$ which is basically a modified Scheil model incorporating back-diffusion, undercooling, and dendrite arm coarsening. The most important extensions as compared to earlier 
models $^{[33,34]}$ are: (1) it can be readily applied to multicomponent alloys; (2) it is directly coupled with PanEngine to obtain the necessary thermodynamic and kinetic data for a multicomponent system; (3) it includes the undercooling effects and dendrite arm coarsening for multicomponent alloys; (4) it considers solid back diffusion during the entire solidification process.

This micro-model can predict the SDAS, microsegregation, types and amounts of non-equilibrium phases in the solidification microstructure of multi-component alloys by incorporating back diffusion in the solidified primary phase, as well as the undercooling and dendrite arm coarsening during solidification. One of the key improvements on the current micro-model needs to be highlighted here. In Yan's work, ${ }^{[37]}$ the diffusivity of each alloying element was hard-coded as impurity diffusion coefficient within the primary ( $\mathrm{Al}$ in Yan's case) phase as a function of temperature. It is well known that the diffusion coefficient of an element within a multi-component system is a function of both composition and temperature. Recently, simulations of diffusion-controlled processes within the CALPHAD framework have made steady progress with the continuous development of diffusion/mobility databases for many materials systems. By coupling thermodynamic database with related atomic mobility database, we are able to calculate the diffusion coefficient of each element within an alloy in relations to its composition and/or temperature. This is especially important for this research since both the phase composition and temperature will continuously change during the solidification process. Therefore, the diffusion coefficients of each component within both the primary $\alpha(\mathrm{Mg})$ phase and the liquid phase can be directly obtained from PanEngine ${ }^{[38]}$ when coupling with the related thermodynamic and mobility databases. In addition, the kinetic parameters used in this work to consider the undercooling and coarsening effects (as listed in Table 1) are organized into a kinetic-parameter database, which can be applied to a series of alloys. In this way, the

Table 1 Main parameters used in the solidification simulation

\begin{tabular}{|c|c|c|c|}
\hline Parameter & Value & Unit & Description \\
\hline$\gamma$ & 0.065 & $\mathrm{~J} / \mathrm{m}^{2}$ & Solid/liquid interfacial energy \\
\hline$\Delta H_{f}$ & $5.5 \times 10^{8}$ & $\mathrm{~J} / \mathrm{m}^{3}$ & Heat of fusion \\
\hline$g$ & 40 & NA & Geometric factor for coarsening \\
\hline$v_{O}$ & 1000 & $\mathrm{~m} / \mathrm{s}$ & Kinetic pre-factor for $\Delta \mathrm{T}_{\mathrm{k}}$ \\
\hline$\alpha_{0}$ & 1 & $\mathrm{~nm}$ & Solute trapping parameter \\
\hline$\delta$ & 28 & NA & Factor of dendrite tip \\
\hline$G$ & $\ldots$ & $\mathrm{K} / \mathrm{m}$ & Thermal gradient \\
\hline$V$ & $\ldots$ & $\mathrm{m} / \mathrm{s}$ & Solidification velocity \\
\hline$C R$ & $\ldots$ & $\mathrm{K} / \mathrm{s}$ & Cooling rate: $C R=G \times V$ \\
\hline
\end{tabular}

predictability of the current solidification module by incorporating the back-diffusion effect has been significantly improved. The architecture of the current PanSolidification module is shown in Fig. 1. With input thermodynamic, mobility, and kinetic-parameter databases as well as solidification conditions (alloy composition, cooling rate, temperature gradient), the solidification microstructure of an alloy under the assigned solidification conditions can be simulated, including solidified phases and their fractions, SDAS, distribution of solutes with each phase etc. As demonstration examples, the microstructural evolution and microsegregation of a series of $\mathrm{Mg}$ alloys ( $\mathrm{Mg}-\mathrm{Al}, \mathrm{Mg}-\mathrm{Al}-\mathrm{Ca}$ and $\mathrm{Mg}-\mathrm{Al}-\mathrm{Sn}$ ) under various solidification conditions are simulated using the PanSolidification module and compared with experimental data of this work and those from literatures.

\section{Numerical Model}

As shown in Fig. 2, a big solid trunk is the primary dendrite arm with fine secondary dendrite arms symmetrically distribute at the sides and the SDAS is indicated as $\lambda_{2}$. A one-dimensional morphology within the interdendritic region of secondary arms is usually used to describe the solidification processing (as enlarged and shown at the bottom part of Fig. 2). Because of the symmetry of the dendrite arms, there is no mass flow through the arm center. Therefore, only one half of the arm spacing is considered. The evolution of the concentration profile for component $i$ in the considered dendrite arm is shown schematically in Fig. 3. $C_{L}^{i}$ and $C_{S}^{i}$ are compositions of solute $i$ within the liquid and solid phases (given the unit of wt.\% in this work), respectively. $V$ is the velocity of $S /$ $L$ interface. During the time interval $\Delta t$, the $S / L$ interface advances $\Delta x_{s}$ (due to solidification) and the length of the solidification region increases by $\Delta L$ (due to the SDAS coarsening). Since this plot has been well discussed in the textbook $^{[8,9,15]}$ for the derivation of the well-known Scheil

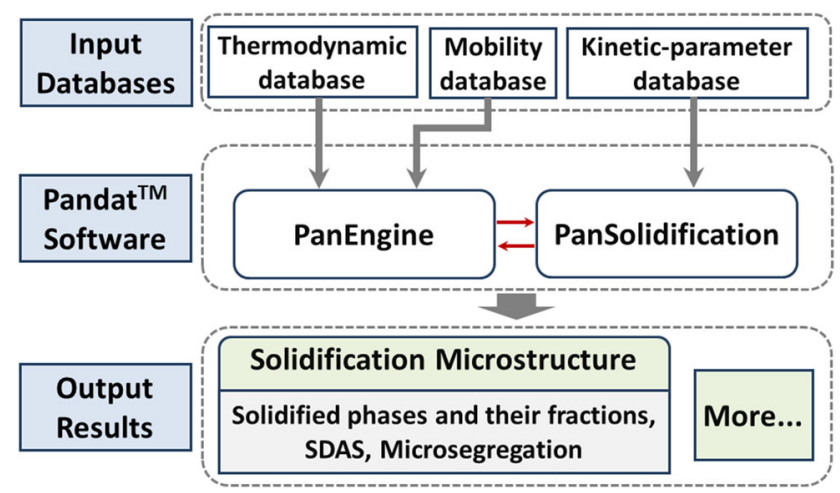

Fig. 1 The architecture of PanSolidification module in Pandat 


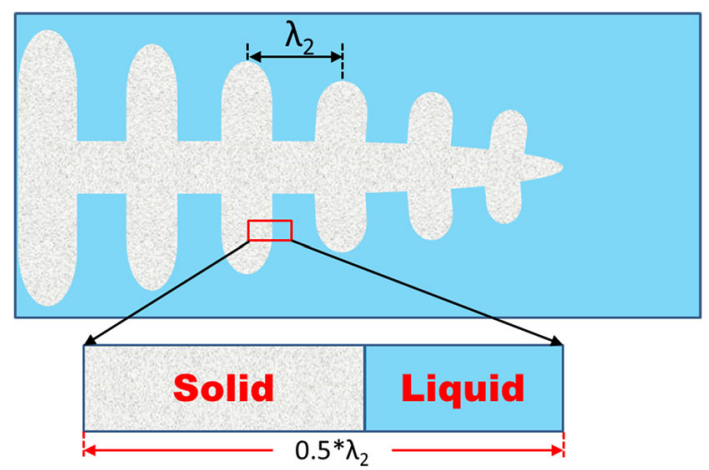

Fig. 2 A schematic diagram of dendrites in the solid and liquid region

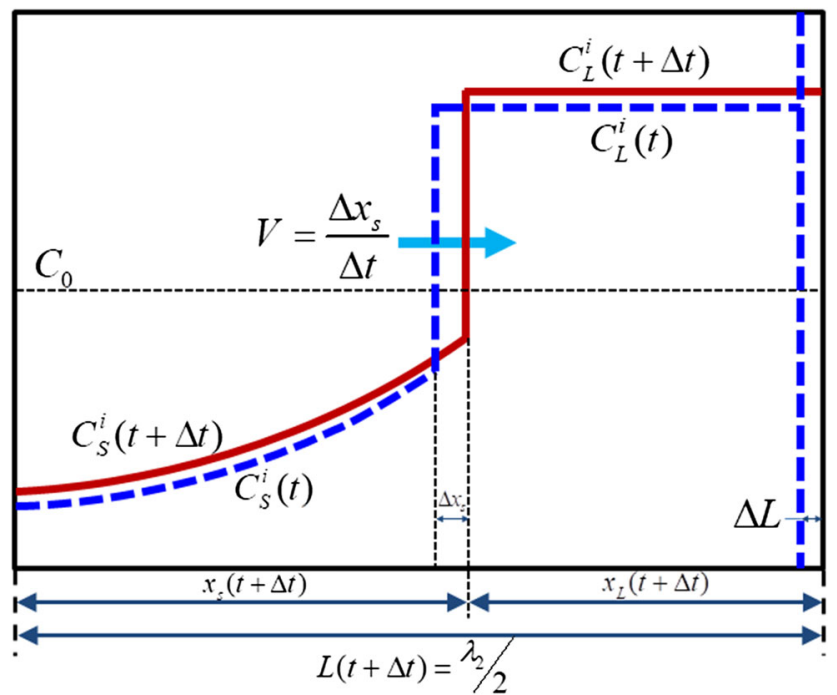

Fig. 3 A schematic plot showing the composition distribution of component $\mathrm{i}$ in a dendrite arm at time $t$ and $t+\Delta t$

equation, no more detailed discussion is given here. For the current solidification simulation at each time step, three major tasks are carried out: (1) calculate the composition of each solute at the $S / L$ interface including the undercooling effects and local-equilibrium conditions; (2) solve the diffusion equations within the solid phase; (3) update the length scale to conserve mass balance for all solute elements. Since these models have been well described in Ref 37 only the undercooling and coarsening micro-models are briefly described below for comprehensive understanding the kinetic parameters used in this work.

Note that we assume that the liquid phase is completely homogeneous in our current model. Thus the diffusion coefficient of the liquid phase can be directly calculated by using the average composition of the liquid phase. In reality, the enrichment of the liquid phase at the $S / L$ interface can be expected especially at very high solidification rate. This effect will results in the exponential liquid composition profile, which will be considered in the future.
Since the solidification rates of our simulations in the current work are relatively low, this enrichment of liquid composition at the $S / L$ boundary may not cause too much difference from assuming completely mixing in the liquid.

\subsection{Micro-model for Undercooling Effects}

Undercooling generally occurs during non-equilibrium of solidification of molten metals and alloys. The level of undercooling influences both the microstructural development via selecting phases during nucleation and the morphological evolution by controlling the growth of the solidified phases. ${ }^{[40]}$ Five types of solidification undercooling have been identified ${ }^{[33]}$ : kinetic undercooling $\Delta T_{k}$, solute trapping undercooling $\Delta T_{g}$, concentration gradient undercooling $\Delta T_{l}$, solutal undercooling $\Delta T_{c}$, and curvature undercooling $\Delta T_{r}$.

The kinetic undercooling is required to transport atoms across the $L / S$ interface.

$\Delta T_{\mathrm{k}}=\frac{V}{v_{0}} \frac{m_{\mathrm{L}}^{\mathrm{e}}}{1-k_{\mathrm{e}}}$

where $m_{\mathrm{L}}^{\mathrm{e}}$ is the liquidus slope and $k_{\mathrm{e}}$ is the equilibrium partition coefficient taken from the equilibrium phase diagram at a fixed temperature. $v_{0}$ is the kinetic pre-factor $^{[41]}$ (approximately the speed of sound).

The undercooling $\Delta T_{1}$ is due to the solute build-up and it's calculation is suggested by Boettinger et al. ${ }^{[42]}$

$\Delta T_{1}=m_{\mathrm{L}}^{\mathrm{e}} c_{\mathrm{L}}^{*}\left[1+\frac{k_{\mathrm{e}}-k_{\mathrm{v}}\left(1-\ln \left(k_{\mathrm{v}} / k_{\mathrm{e}}\right)\right.}{1-k_{\mathrm{e}}}\right]$

$k_{v}$ is the velocity-dependent partition coefficient according to the work of Aziz et al. ${ }^{[43]}$

$k_{\mathrm{v}}=\frac{a_{0} V / D_{\mathrm{i}}+K_{\mathrm{e}}}{a_{0} V / D_{\mathrm{i}}+1-\left(1-K_{\mathrm{e}}\right) C_{\mathrm{L}}^{\mathrm{v}}}$

$a_{O}$ is the solute trapping parameter $(0.5-5 \mathrm{~nm})$ which is related to the interatomic distance in the liquid close to the surface and $K_{\mathrm{e}}$ is a partitioning parameter ${ }^{[44]}$.

$K_{\mathrm{e}}=\frac{k_{\mathrm{e}}\left(1-C_{\mathrm{s}}^{\mathrm{e}}\right)}{1-C_{\mathrm{L}}^{\mathrm{e}}}$

$C_{\mathrm{s}}^{\mathrm{e}}$ and $C_{\mathrm{L}}^{\mathrm{e}}$ are the equilibrium compositions of the liquid and solid at the temperature of a flat interface. The interface diffusion coefficient $D_{i}$ is not known, so its upper limit given by the liquid diffusion coefficient $\left(D_{\mathrm{L}}\right)$ will be used.

The relation between $C_{\mathrm{L}}^{\mathrm{e}}$ and $C_{\mathrm{L}}^{\mathrm{v}}$ is shown below:

$C_{\mathrm{L}}^{\mathrm{e}}=C_{\mathrm{L}}^{\mathrm{v}} \frac{1-k_{\mathrm{v}}+k_{\mathrm{v}} \ln \left(k_{\mathrm{v}} / k_{\mathrm{e}}\right)}{1-k_{\mathrm{e}}}+\frac{V}{v_{0}\left(1-k_{\mathrm{e}}\right)}$ 
The gradient undercooling $\Delta T_{\mathrm{g}}$ is described by Bower et al. ${ }^{[45]}$

$$
\Delta T_{\mathrm{g}}=\frac{D_{\mathrm{L}}^{\mathrm{g}} G}{V}
$$

where $G$ is temperature gradient at the $S / L$ interface and the diffusion coefficient $D_{\mathrm{L}}^{\mathrm{g}}$ is calculated by assuming the isothermal condition within the liquid.

The solutal undercooling $\Delta T_{\mathrm{c}}$ can be described as:

$$
\Delta T_{\mathrm{c}}=m_{\mathrm{L}}^{\mathrm{c}} \Delta C_{\mathrm{c}}=m_{\mathrm{L}}^{\mathrm{c}} \frac{\left(1-k_{\mathrm{v}}\right) \operatorname{Iv}\left(P_{\mathrm{c}}\right)}{1-\left(1-k_{\mathrm{v}}\right) \operatorname{Iv}\left(P_{\mathrm{c}}\right)}\left(C_{0}-\Delta C_{\mathrm{g}}\right)
$$

$I v\left(P_{\mathrm{c}}\right)$ is the Ivantsov function ${ }^{[9]}$ and the Peclet number $P_{c}$ of the solute diffusion at the tip.

The curvature undercooling $\Delta T_{r}$ for a sphere with a radius $r_{\mathrm{T}}$ can be described as:

$\Delta T_{\mathrm{r}}=\frac{2 \gamma T_{\mathrm{T}}}{\Delta H_{\mathrm{f}} r_{\mathrm{T}}}$

When the plate and cylinder geometries are assumed, the value of $\Delta T_{\mathrm{r}}$ will be zero.

\subsection{Micro-model for Dendrite Arm Coarsening}

The initial SDAS is about twice of the dendrite tip radius: $\lambda_{0} \cong 2 r_{\mathrm{T}}$ and $r_{\mathrm{T}}$ is described as a function of initial alloy composition, growth rate, and independent of temperature gradient ${ }^{[46,47]}$

$r_{\mathrm{T}}^{2}=\frac{2 \gamma D_{\mathrm{L}} T_{0} \delta}{V \Delta T_{0} k_{\mathrm{e}} \Delta H_{\mathrm{f}}}$

where $V, \Delta T_{0}, k_{\mathrm{e}}$ are the interface solidification velocity, freezing temperature range, and equilibrium partition coefficient, respectively. $\delta$ is a constant being dependent on the harmonic of the perturbation.

The dendrite arm spacing needs to be known since it sets the diffusion distances in the liquid and solid phases. Owing to the remelting and resolidification mechanism, dendrite arm coarsening contributes significantly to homogenization during solidification. ${ }^{[22]}$ The calculation of coarsening is described as in Ref 48 :

$\lambda^{3}-\lambda_{0}^{3}=\int_{0}^{t} g M \mathrm{~d} t$

$\lambda_{0}$ is the initial SDAS obtained from the calculated dendrite tip radius as described in above $\mathrm{Eq} 2.9$, and $\lambda$ is the model predicted SDAS at a certain time. $M$ is coarsening parameter which is proportional to $\lambda^{1 / 3}, t$ is time and $g$ is the geometry factor representing the influence of the dendrite geometry.

For a binary system, the coarsening parameter $M$ is defined as ${ }^{[49]}$ :

$M=\frac{\gamma D_{\mathrm{L}} T}{\Delta H_{\mathrm{f}} m_{\mathrm{L}}^{\mathrm{v}}\left(1-k_{\mathrm{v}}\right) C_{\mathrm{L}}^{\mathrm{v}}}$

For a multicomponent system, the coarsening parameter must be calculated separately for each alloying element. Then, the following model is used to take into consideration all the solute elements ${ }^{[37]}$.

$M=\frac{1}{\sum_{j=1}^{n} 1 / M_{j}}$

It should be emphasized that all multicomponent phase diagram related quantities given in sections 2.1 and 2.2 (such as $\mathrm{m}_{\mathrm{L}}$ and $k_{\mathrm{e}}$ ) are directly calculated via PanEngine $^{[38]}$ at each time step by assuming the local equilibrium at the liquid/solid interface.

\section{Experimental Methodology}

Experimental alloys studied in this work were made of pure $\mathrm{Mg}, \mathrm{Al}$, and/or a Mg-33Ca master alloy. (All compositions are in weight percent unless otherwise stated.) They were melted and cast in a boron nitride coated mild steel crucible under a protective gas mixture of $\mathrm{CO}_{2}+0.7 \% \mathrm{SF}_{6}$. Small pieces of $\mathrm{Mg}-4 \mathrm{Al}$ and $\mathrm{Mg}-\mathrm{Al}-\mathrm{Ca}$ alloys were then remelted and sucked into stainless steel tubes with $4 \mathrm{~mm}$ in diameter and $450 \mathrm{~mm}$ in length. The stainless steel tube was then put into a furnace with the axial temperature gradient maintained at $4{ }^{\circ} \mathrm{C} / \mathrm{mm}$ by three independently controlled heating coils and water cooling jacket at the bottom. The sample was directionally solidified as cylindrical rods in the stainless steel tube under a certain cooling rate controlled by its downward moving speed. The influence of various fast cooling rates on solidification microstructure was also investigated using wedge die casting. Ternary AT72 magnesium alloy (Mg-7Al-2Sn) was prepared using wedge casting. Cooling rates at four different locations from the top to the tip of the wedge die were measured using k-type thermo-couples. Wedge casting samples were cut from locations near the cooling-rate measurements. One gravity casting specimen of AT72 alloy in cylindrical steel mold was also prepared. All samples were then mechanically polished for microstructural investigation. Optical microscopy and scanning electron microscopy (LEO-1530 and FEI Apreo) were used for microstructure characterization, and an electron probe micro-analyzer (EPMA) of CAMECA SX-50 was used for microsegregation measurements. The grid scan method (as 


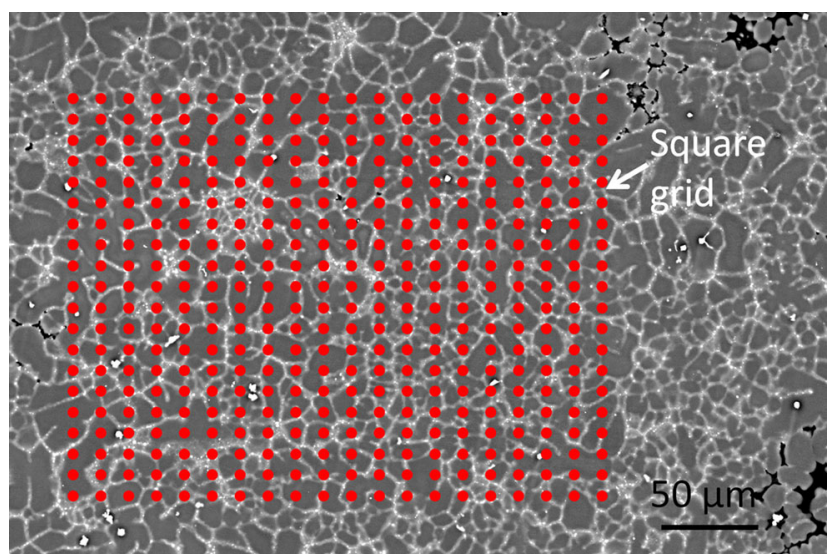

Fig. 4 Schematic illustration of EPMA grid scan on representative microstructure of die cast AT72 alloy. Each red dot in the image represents one EPMA data acquisition location (Color figure online)

shown in Fig. 4) was employed in the present study for microsegregation investigation. The square grid consists of 400 acquisition positions with $10 \mu \mathrm{m}$ increment and chemical compositions on all positions were measured using EMPA. The acquired composition data were then sorted using the Flemings-Gungor (F-G) method. ${ }^{[50,51]}$

\section{Discussion}

\subsection{Mg-Al Binary Alloys}

Figure 5 shows typical optical microstructures of directionally solidified $\mathrm{Mg}-4 \mathrm{Al}$ alloys under the cooling rates of (a) 0.2 and (b) $0.8 \mathrm{~K} / \mathrm{s}$. These specimens were cut along the growth direction (from left to right) to study the variations of the solid/liquid interface morphology. The morphology of the solid formed from the quenched liquid clearly reveals the solid/liquid interface at the moment of quenching. Behind the interface is the mushy zone, where the solid and the liquid coexist. Two types of phases are shown in this region, the white phase is $\alpha(\mathrm{Mg})$ and the dark one is the quenched interdendritic liquid. The morphology of the $\alpha(\mathrm{Mg})$ phase shows primary trunks and finer secondary and tertiary arms, typical of well-developed dendrites. Both the PDAS and SDAS decrease with the increasing cooling rate. The microstructural evolutions of $\mathrm{Mg}-3$, 6, and 9Al alloys under different solidification conditions were investigated by Paliwal et al. ${ }^{[52,53]}$ The variation of SDAS for Mg-Al alloys with cooling rate and Al composition was experimentally characterized. As shown in Fig. 6, the SDAS decreases linearly with the increasing cooling rate in a logarithm scale as expected. Also, the SDAS decreases with the increasing Al composition under the same cooling rate, which is likely attributed to the decreased interfacial energy with the increasing $\mathrm{Al}$ composition in the Ref 54

Figure 7 shows the simulated $\mathrm{Al}$ composition profiles within the $\mathrm{Mg}-4 \mathrm{Al} \alpha(\mathrm{Mg})$ phase under the cooling rates of both 0.2 and $0.8 \mathrm{~K} / \mathrm{s}$. The experimental measurements of this work and the calculated results using the Scheil model are superimposed in the same plot as well. It is not surprising to see the large discrepancies between the Scheil simulation (without considering the back-diffusion within the solid phases) and the experimental measurements, and such discrepancies increase with the decreasing cooling rate. When the back-diffusion effect is taken into

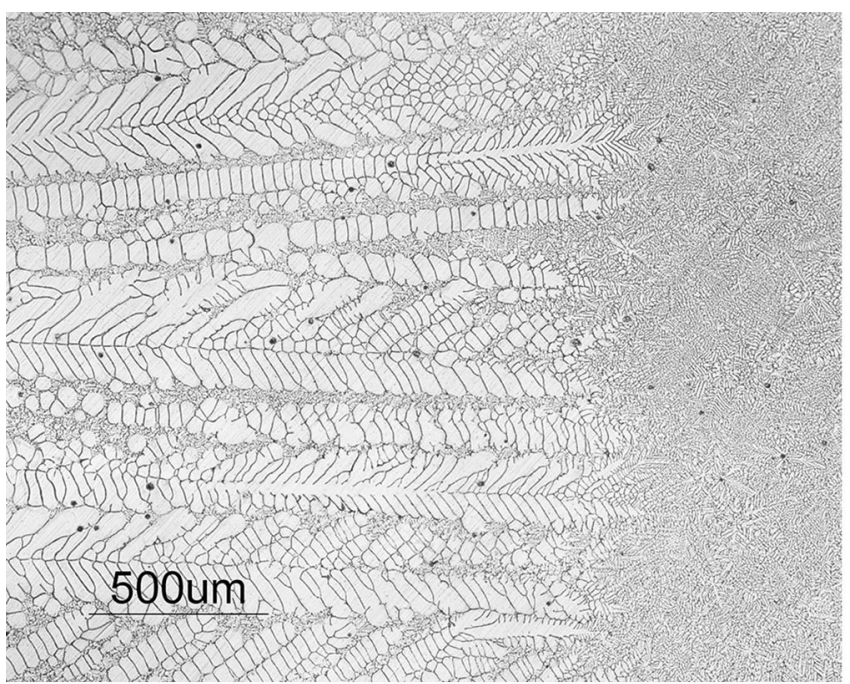

(a)

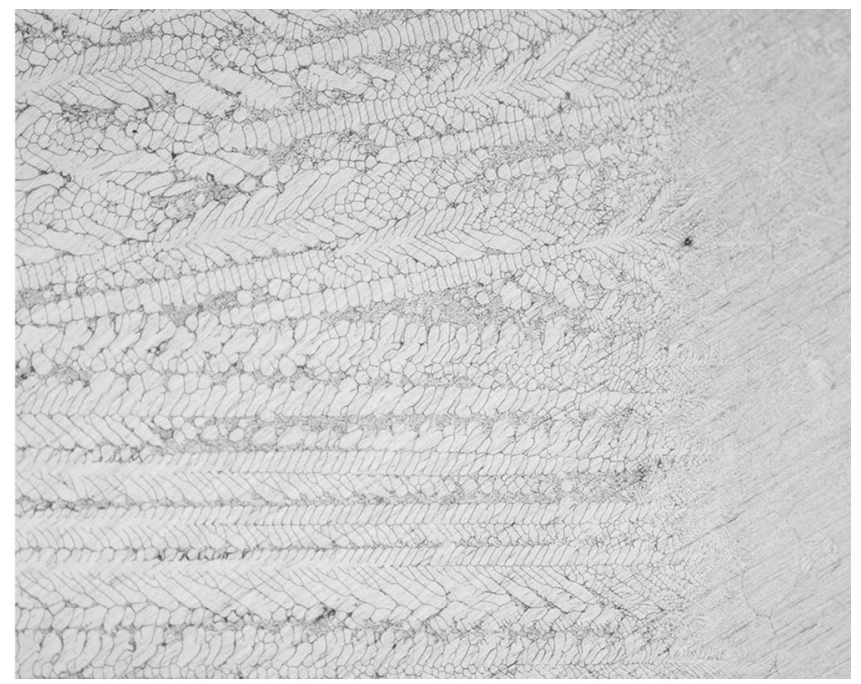

(b)

Fig. 5 Optical micrographs showing typical microstructures of directionally solidified $\mathrm{Mg}-4 \mathrm{wt}$ \% Al alloys under various cooling rates: (a) $0.2 \mathrm{~K} / \mathrm{s}$; and (b) $0.8 \mathrm{~K} / \mathrm{s}$ 


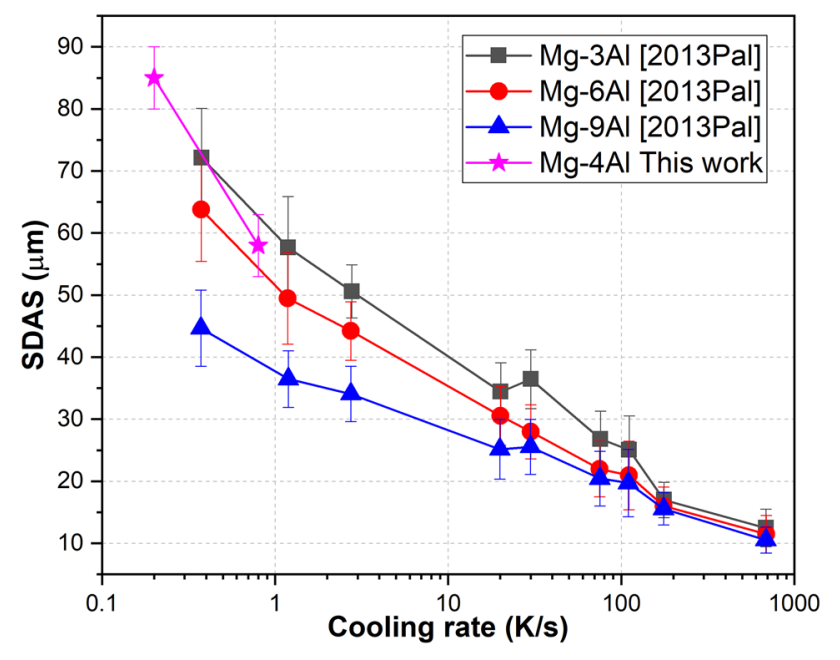

Fig. 6 Experimentally measured SDAS values of $\mathrm{Mg}-\mathrm{Al}$ binary alloys vs. cooling rate

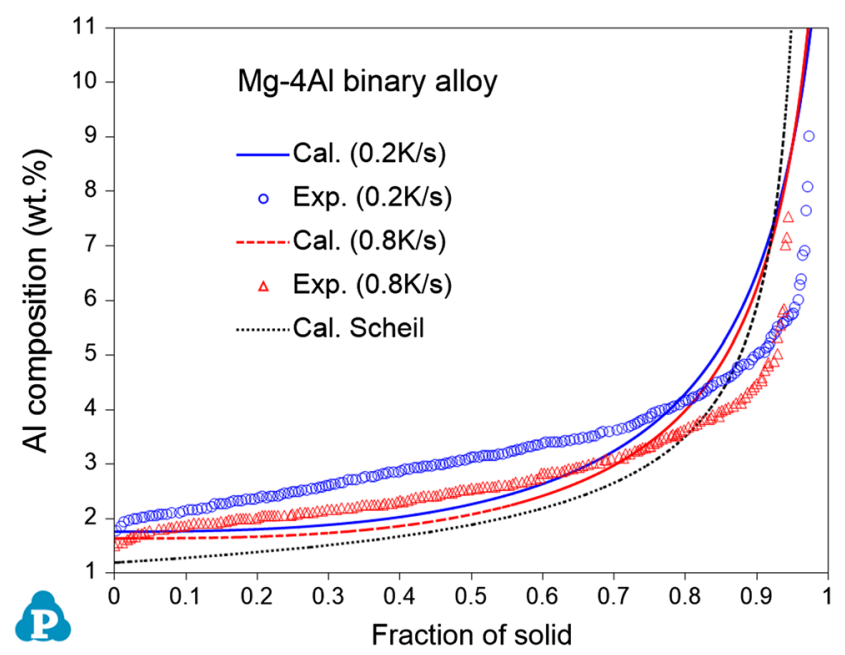

Fig. 7 Comparison between the simulated and measured (this work) $\mathrm{Al}$ composition profiles vs. $f_{\mathrm{s}}$ in the $\alpha(\mathrm{Mg})$ phase of the $\mathrm{Mg}-4 \mathrm{Al}$ alloy

consideration, the simulation results agree better with the experimental results, especially for the initial composition at the center of the $\alpha(\mathrm{Mg})$ phase $\left(f_{\mathrm{s}}=0\right)$. However, there are still considerable discrepancies between the simulations and measurements, which can be explained in two possible ways: One is due to the inaccuracy of micro-models and/or model parameters; the other is from the errors in experimental measurement and/or improper data analysis methods. For the modeling part, improvements on the micromodels and calibration of model parameters are still ongoing, which requires reliable experimental data as references.

The $\mathrm{Al}$ distribution within the $\alpha(\mathrm{Mg})$ dendrites was measured using EPMA with the area-scan method. A total of 400 points within a square area were measured automatically and then linearly normalized as described in Ref
55. It is noted that the electron beam used for microanalysis has a certain impact area depending on the accelerating voltage, thus, the detected information is not exactly from the point where the electron beam was placed. This makes it extremely difficult to obtain accurate compositions of a phase with very small size, such as eutectic phases within the interdendritic regions. From the statistical viewpoint, the portion of points located on the dendrites equals to the fraction of the primary phase. While due to the beam impact area limitations, the portion of collected data from the primary phase dendrites is slightly higher than its phase fraction. On the other hand, the morphology of the primary dendrite from the transverse section looks like a disk with radial growth. Away from the center of the dendrite, the area of annulus with same thickness will increase with increasing distance from the center. Therefore, the linearly normalized experimental measurements may not be able to rationally represent the actual distribution of solute within the $\alpha(\mathrm{Mg})$ phase.

In addition to comparing the calculated and measured microsegregation of $\mathrm{Al}$ within the $\alpha(\mathrm{Mg})$ phase, the fractions of interdendritic phases and SDAS are also critical to validate the reliability of the simulated results. As reported in our previous work, the measured fractions of the interdendritic phases, which include both $\alpha(\mathrm{Mg})$ and $\gamma\left(\mathrm{Mg}_{17}\right.$ $\mathrm{Al}_{12}$ ), are 3.7 and $3.3 \%$ under the cooling rate of 0.2 and $0.8 \mathrm{~K} / \mathrm{s}$, respectively. The simulated fractions of the interdendritic phases are $1.7 \%$ for the cooling rate of $0.2 \mathrm{~K} /$ $\mathrm{s}$ and $1.3 \%$ for the cooling rate of $0.8 \mathrm{~K} / \mathrm{s}$. Even though the absolute values are different, the trend of phase fraction changes with cooling rate is the same. Also, these values are within the uncertainty of image analysis especially for the etched samples where the fractions of interdendritic regions are usually enlarged. The simulated SDAS of Mg4Al alloys solidified under 0.2 and $0.8 \mathrm{~K} / \mathrm{s}$ are 89 and $55 \mu \mathrm{m}$, respectively, which agree well with the experimentally measured values as listed in Table 2 .

The kinetic parameters and input conditions for the current simulations are listed in Tables 1 and 2. In order to explore the extendibility and predictability of the current method, solidification simulations of different series of alloys under different cooling rates are carried out by using the same series of kinetic parameters (as listed in Table 1). As shown in Fig. 8, the simulated $\mathrm{Al}$ composition profiles in the $\mathrm{Mg}-\mathrm{xAl}(x=3,6,9) \alpha(\mathrm{Mg})$ phase at the cooling rate of $0.375 \mathrm{~K} / \mathrm{s}$ are in good agreement with the experimental measurements in Ref 53. The comparison between the calculated and measured SDAS of Mg-Al binary alloys both from this work and Ref 52 also shows good agreement (as shown in Fig. 9). It should be noted that the same $S /$ $L$ interfacial energy $\left(\gamma=0.065 \mathrm{~J} / \mathrm{m}^{2}\right)$ and same coarsening geometric factor (40) are used for all simulations. The good agreement between the simulated and measured SDAS 
Table 2 Summary of Mg alloys simulated in this work

\begin{tabular}{|c|c|c|c|c|c|}
\hline Composition, wt.\%) & Thermal gradient, $\mathrm{G}$ & Solidification velocity, $\mathrm{V}$ & Cooling rate, $\mathrm{CR}$ & SDAS, $\mu \mathrm{m}$ & References \\
\hline $\mathrm{Mg}-3 \mathrm{Al}$ & $7.5 \times 10^{3}$ & $5.0 \times 10^{-5}$ & 0.375 & 70 & 52,53 \\
\hline $\mathrm{Mg}-3 \mathrm{Al}$ & $4.26 \times 10^{2}$ & $2.58 \times 10^{-3}$ & 1.1 & 56 & 52,53 \\
\hline $\mathrm{Mg}-4 \mathrm{Al}$ & $4 \times 10^{3}$ & $5.0 \times 10^{-5}$ & 0.2 & 85 & This work \\
\hline Mg-4Al & $4 \times 10^{3}$ & $2.0 \times 10^{-4}$ & 0.8 & 58 & This work \\
\hline Mg-6Al & $7.5 \times 10^{3}$ & $5.0 \times 10^{-5}$ & 0.375 & 64 & 52,53 \\
\hline Mg-6Al & $4.26 \times 10^{2}$ & $2.58 \times 10^{-3}$ & 1.1 & 47 & 52,53 \\
\hline $\mathrm{Mg}-9 \mathrm{Al}$ & $7.5 \times 10^{3}$ & $5.0 \times 10^{-5}$ & 0.375 & 45 & 52,53 \\
\hline Mg-9Al & $4.26 \times 10^{2}$ & $2.58 \times 10^{-3}$ & 1.1 & 36 & 52,53 \\
\hline $\mathrm{Mg}-4 \mathrm{Al}-4 \mathrm{Ca}$ & $4 \times 10^{3}$ & $1.0 \times 10^{-4}$ & 0.4 & $\ldots$ & This work \\
\hline $\mathrm{Mg}-5 \mathrm{Al}-3 \mathrm{Ca}$ & $4 \times 10^{3}$ & $3.0 \times 10^{-5}$ & 0.12 & $\ldots$ & This work \\
\hline $\mathrm{Mg}-7 \mathrm{Al}-2 \mathrm{Sn}$ & $3.674 \times 10^{3}$ & $1.5 \times 10^{-2}$ & 55 & $\ldots$ & This work \\
\hline $\mathrm{Mg}-7 \mathrm{Al}-2 \mathrm{Sn}$ & $5.33 \times 10^{2}$ & $1.5 \times 10^{-2}$ & 8 & 19 & This work \\
\hline $\mathrm{Mg}-7 \mathrm{Al}-2 \mathrm{Sn}$ & $1 \times 10^{3}$ & $1.5 \times 10^{-2}$ & 15 & 17 & This work \\
\hline $\mathrm{Mg}-7 \mathrm{Al}-2 \mathrm{Sn}$ & $1.67 \times 10^{3}$ & $1.5 \times 10^{-2}$ & 25 & 13 & This work \\
\hline $\mathrm{Mg}-7 \mathrm{Al}-2 \mathrm{Sn}$ & $1 \times 10^{4}$ & $1.5 \times 10^{-2}$ & 150 & 6.2 & This work \\
\hline
\end{tabular}

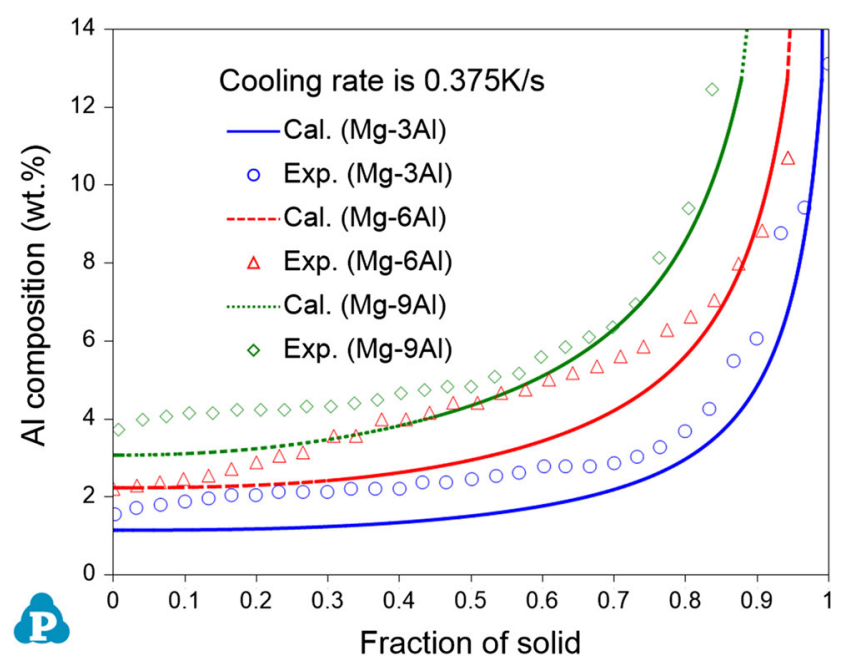

Fig. 8 Comparison between the simulated and measured ${ }^{[53]} \mathrm{Al}$ composition profiles vs. $f_{\mathrm{s}}$ in the $\alpha(\mathrm{Mg})$ phase of $\mathrm{Mg}$-xAl $(x=3$, $6,9)$ alloys

results indicates that the $S / L$ interfacial energy may not be the most important factor, at least for $\mathrm{Mg}-\mathrm{Al}$ binary alloys, to affect the relationship of the SADS and the cooling rate as explained in Ref 54. The simulations in this study suggest that the solidification rate has significant effect on the final SDAS as well.

\subsection{Mg-Al-Ca Ternary Alloys}

In order to further verify the feasibility of our new models, solidification simulations have been extended to higherorder systems, such as Mg-Al-Ca and Mg-Al-Sn ternary

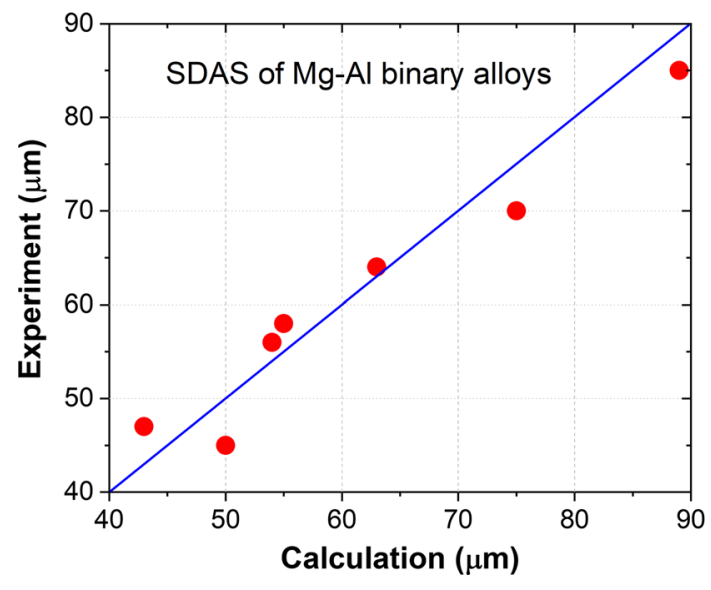

Fig. 9 Comparison between the simulated and measured SDAS results of $\mathrm{Mg}-\mathrm{Al}$ binary alloys

alloys. As reported in our previous work, ${ }^{[56]}$ the microsegregations of solutes within two ternary $\mathrm{Mg}-\mathrm{Al}-\mathrm{Ca}$ alloys (Mg-4Al-4Ca and $\mathrm{Mg}-5 \mathrm{Al}-3 \mathrm{Ca}$ ) were experimentally investigated. Using the same kinetic parameters derived from the $\mathrm{Mg}$-Al binary alloys, solidification simulations were conducted for the $\mathrm{Mg}-4 \mathrm{Al}-4 \mathrm{Ca}$ alloy at the cooling rate of $0.2 \mathrm{~K} / \mathrm{s}$ and the $\mathrm{Mg}-5 \mathrm{Al}-3 \mathrm{Ca}$ alloy at $0.12 \mathrm{~K} / \mathrm{s}$, respectively. Comparisons of the simulated composition profiles with experimental measurements for both alloys are shown in Fig. 10. As shown in Fig. 10(a), the simulated $\mathrm{Al}$ composition profiles for both alloys are in good agreement with experimental measurements in Ref 56. The abrupt changes of $\mathrm{Al}$ compositions at $\mathrm{f}_{\mathrm{s}} \approx 0.73$ are due to the formation of Laves_C36 phase. It is also noted that the trend of $\mathrm{Al}$ composition change within both 


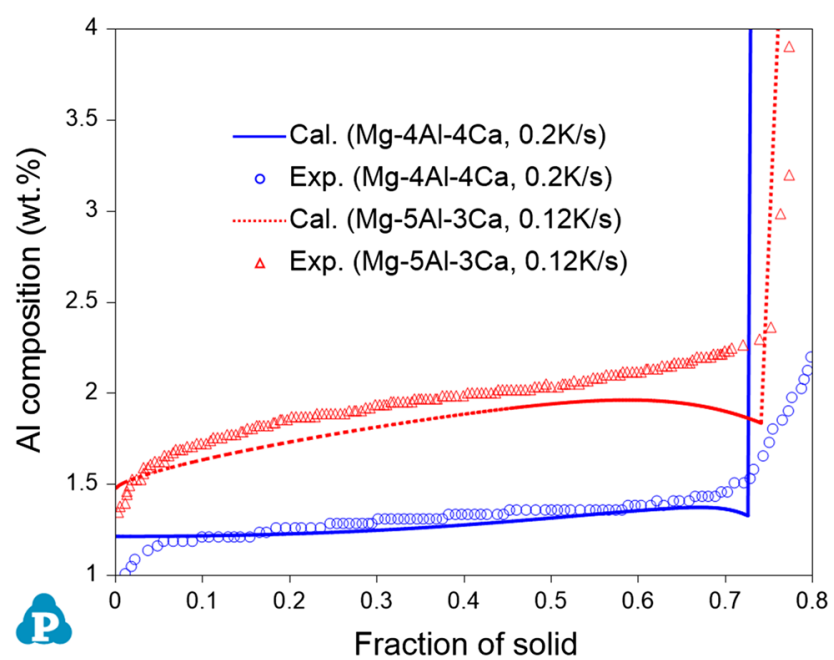

(a)

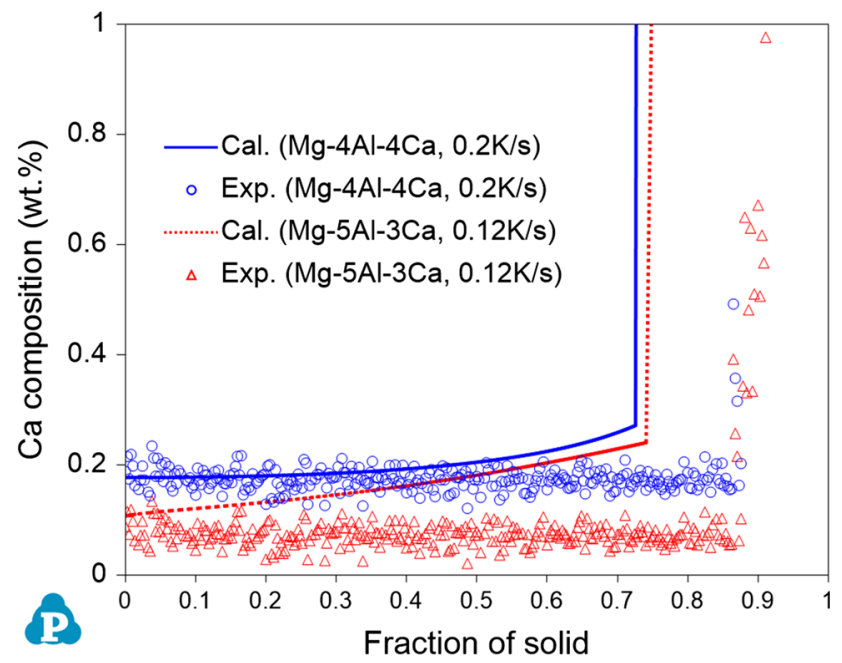

(b)

Fig. 10 Comparison between the simulated and measured (this work) composition profiles vs. fs in the $\alpha(\mathrm{Mg})$ phase of $\mathrm{Mg}-\mathrm{Al}-\mathrm{Ca}$ alloys: (a) $\mathrm{Al}$; and (b) $\mathrm{Ca}$

alloys is different, which is also due to the formation of the Laves_C36 phase. When the Laves_C36 phase is formed, it consumes a large amount of $\mathrm{Al}$ from the liquid phase in front of the $S / L$ interface and creates an Al-lean region at the $S / L$ interface. Thus, the Al solute within the previously solidified $\alpha(\mathrm{Mg})$ phase could back diffuse to the Al-lean region. Therefore, the $\mathrm{Al}$ composition drops especially at the region close to the $S / L$ interface. However, no obvious drops were found on the $\mathrm{Al}$ composition for the $\mathrm{Mg}-\mathrm{Al}$ binary alloys, which may due to the relatively lower fraction of the $\gamma\left(\mathrm{Mg}_{17} \mathrm{Al}_{12}\right)$ formed. Since our experimental data were sorted in the ascending order, the tendency of solute concentration drop at the $S / L$ interface was artificially eliminated, which results in large discrepancy at the region close to the $S / L$ interface. The comparisons between the simulated and measured $\mathrm{Ca}$ composition profiles for both Mg-Al-Ca alloys are shown in Fig. 10(b). There are no significant changes on the $\mathrm{Ca}$ composition profiles for both $\mathrm{Mg}-\mathrm{Al}-\mathrm{Ca}$ alloys, which is due to the small solubility (less than $0.2 \mathrm{wt} . \%$ ) and the relatively larger diffusivity (one magnitude order higher than $\mathrm{Al}$ ) of $\mathrm{Ca}$ within the $\alpha(\mathrm{Mg})$ phase. $^{[57]}$

\subsection{Mg-Al-Sn Ternary Alloy}

Solidification simulations carried out above are all under low cooling rates $(0.12 \sim 0.8 \mathrm{~K} / \mathrm{s})$ via directional solidification experiments. Most of the $\mathrm{Mg}$ components are die castings with high cooling rates from 50 to $200 \mathrm{~K} / \mathrm{s}$ or even higher. Thus, it is necessary to validate current method under higher cooling rate as well. Figure 11 shows the ascast microstructure of wedge-casting AT72 alloy under cooling rates ranging from $10-150 \mathrm{~K} / \mathrm{s}$. The DS microstructure has the characteristics of columnar growth as shown in Fig. 5, while the microstructure of wedgecasting AT72 has near-equiaxed dendritic structure due to fast cooling rates. Fast cooling rates also greatly refine the SDAS. Experimentally measured SDAS of four different cooling rates $(8,15,25$, and $150 \mathrm{~K} / \mathrm{s})$ are shown in Fig. 12 and compared with simulation results. It can be seen that simulation results match very well with the experimental results over a wide range of cooling rates.

Microsegregation of the AT72 alloy using gravity casting in a cylindrical steel mold was investigated under a cooling rate of $55 \mathrm{~K} / \mathrm{s}$. The microstructure of this diecasting alloy involves small-size equiaxed dendrites. The small size of $\alpha(\mathrm{Mg})$ phase makes the experimental measurements of the microsegregation extremely difficult. This is the reason we choose this relatively low die-cast cooling rate to ensure the maneuverability and reliability of our microsegregation investigation using EPMA on the fine microstructure. The comparison between the simulated and measured composition profiles in the $\alpha(\mathrm{Mg})$ phase of AT72 is shown in Fig. 13. The simulated Sn composition profile well describes the experimental result. The simulated $\mathrm{Al}$ composition profile agrees well with the experimental measurements at low $f_{s}$, while a large discrepancy is found at high $\mathrm{f}_{\mathrm{s}}$ which may due to the formation of intermetallic Laves_C14 $\left(\mathrm{Mg}_{2} \mathrm{Sn}\right)$ phase. This discrepancy could also be introduced from the EPMA measurements. Due to the fine microstructure, the electron beam impact region may cover area closing to the center of the $\alpha(\mathrm{Mg})$ phase (with higher Al concentration) even place the beam at the edge of the $\alpha(\mathrm{Mg})$ phase. Thus, the measured $\mathrm{Al}$ composition within the $\alpha(\mathrm{Mg})$ phase will be higher than the true value. Due to the small solubility of $\mathrm{Sn}$ within the $\alpha(\mathrm{Mg})$ phase, the 


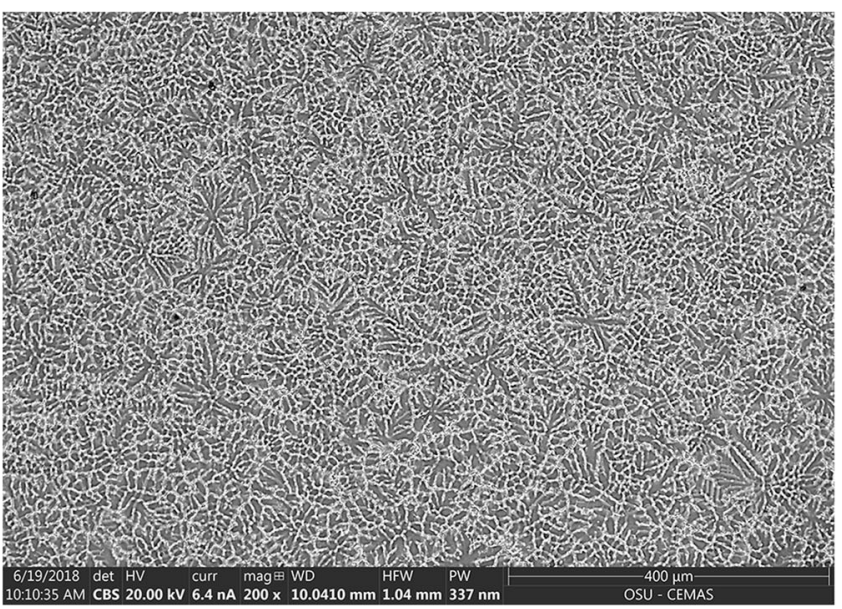

(a)

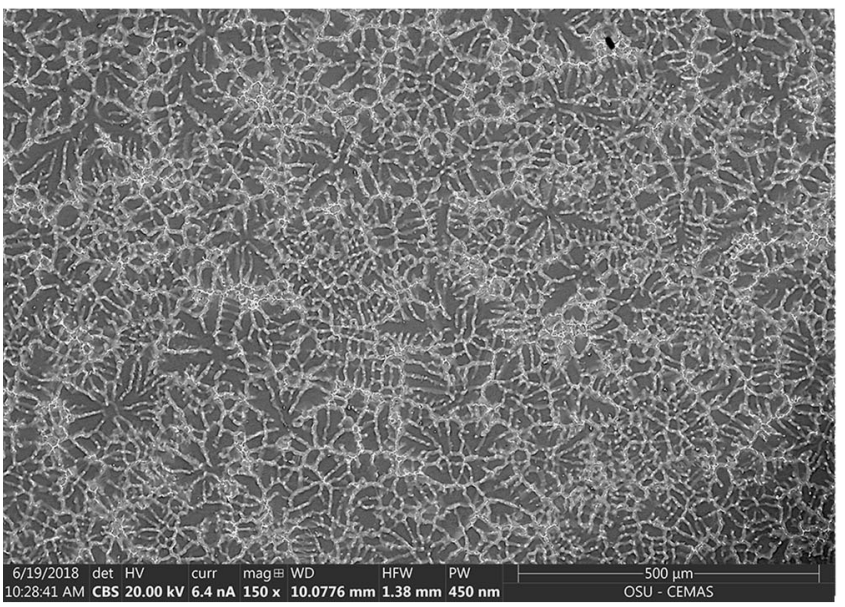

(c)

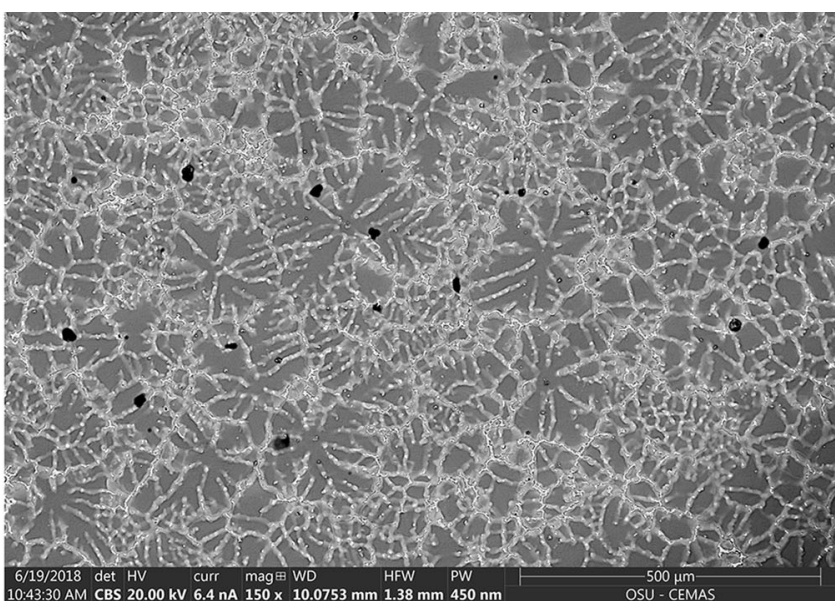

(b)

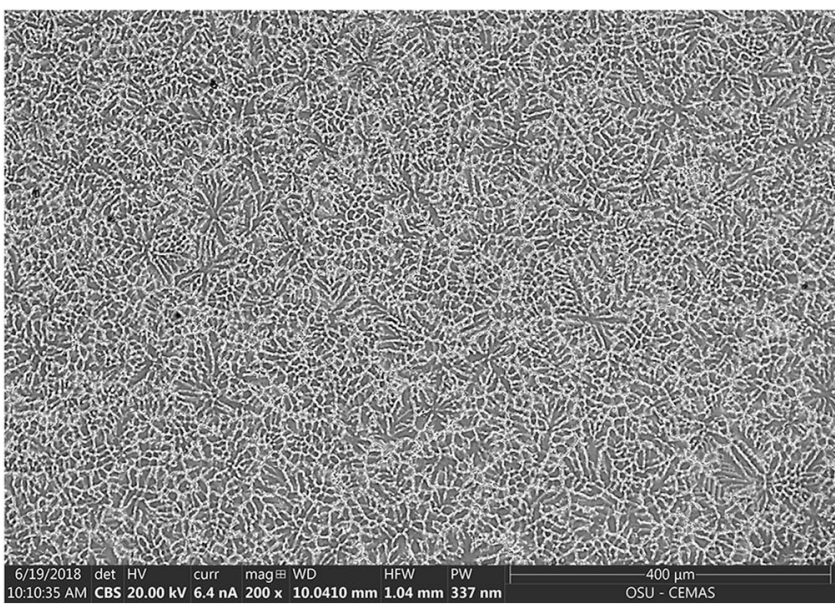

(d)

Fig. 11 SEM images of as-cast microstructure of wedge-casting AT72 alloy under different cooling rates: (a) $8 \mathrm{~K} / \mathrm{s}$; (b) $15 \mathrm{~K} / \mathrm{s}$; (c) $25 \mathrm{~K} / \mathrm{s}$; and (d) $150 \mathrm{~K} / \mathrm{s}$

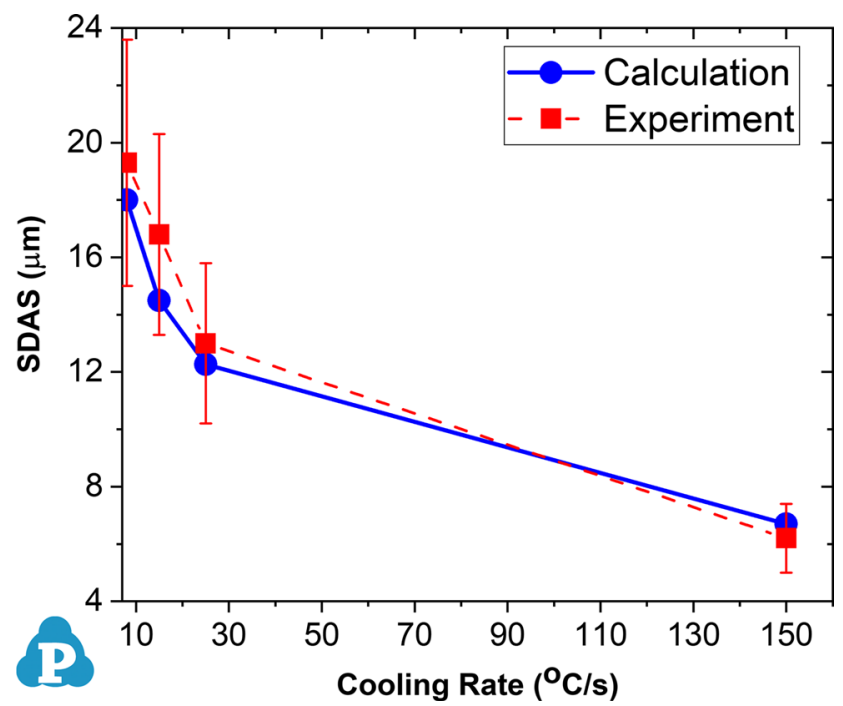

Fig. 12 Comparison between simulated and measured SDAS of wedge casting AT72 alloy

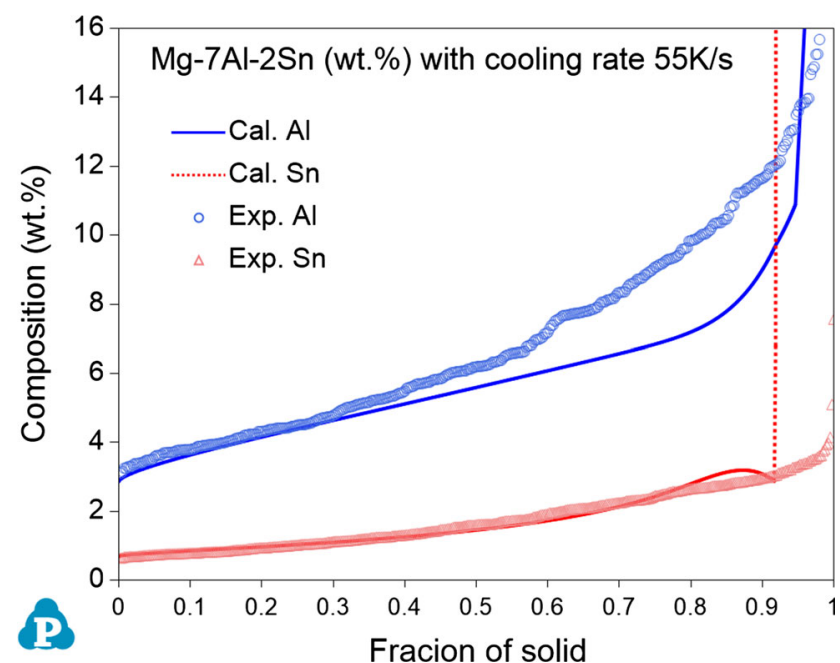

Fig. 13 Comparison between the simulated and measured (this work) composition profiles vs. $f_{\mathrm{s}}$ in the $\alpha(\mathrm{Mg})$ phase of $\mathrm{Mg}-7 \mathrm{Al}-2 \mathrm{Sn}$ alloy 
additional contribution from the beam impact region is smaller than that of Al. This explains the better agreement between the simulated and measured Sn composition profiles. There is a drop on the simulated $\mathrm{Sn}$ composition profile when the secondary intermetallic phase form, while there is no drop on the simulated $\mathrm{Al}$ composition profile. This is because the formation of intermetallic Laves_C14 $\left(\mathrm{Mg}_{2} \mathrm{Sn}\right)$ phase only consumes solute $\mathrm{Sn}$, not $\mathrm{Al}$.

As discussed in this section, the accuracy and reliability of our model predictions will strongly depend on the experimental microsegregation data. From the experimental side, three critical steps need to be emphasized here for accurate microsegregation investigation of $\mathrm{Mg}$ alloys:

(1) Sample preparation. As show in the current study, the uniform microstructures of the directionally solidified Mg alloys under controlled cooling condition are more suitable for qualitative microsegregation investigations. One needs to pay attention to the tube container which holds the melt of $\mathrm{Mg}$ alloy for DS since it may cause the soldering problem. Mirković et al. ${ }^{[58]}$ investigated the soldering problem of $\mathrm{Mg}$-Al-based magnesium for DS with various steel tubes. The extensive reactions were found between the $\mathrm{Mg}$ melts and various unprotected steel containers. Therefore, an integrated approach comprised of the dedicated $\mathrm{BN}$ coating protection of steel tube materials was developed. Apparently, the comprehensive work of Mirković et al. ${ }^{[58]}$ provided useful guideline for the sample preparation of $\mathrm{Mg}$ alloys during solidification process. Note that, our DS work for both the $\mathrm{Mg}-\mathrm{Al}$ and $\mathrm{Mg}-\mathrm{Al}-\mathrm{Ca}$ alloys was carried out earlier than that in Ref 58 and we used the uncoated stainless steel tubes. We did find a dark layer between the DS specimen and the steel tube, but it is very thin and even not observable under optical microscope. The ignorable soldering problem for our DS $\mathrm{Mg}$ alloys may due to two possibilities: relatively lower $\mathrm{Al}$ content (4 wt.\%) and lower processing temperatures $\left(\sim 700{ }^{\circ} \mathrm{C}\right)$ in our DS experiments. On the other hand, our microsegregation measurements were performed at the center area of our DS specimens, which may also reduce the possible errors introduced by the soldering problem.

(2) Microsegregation measurement. Since some issues concerning experimental microsegregation measurements have been well discussed both in above sections and in the work of Lacaze et al., ${ }^{[59]}$ no further discussions are needed here in order to save space.

(3) Microsegregation data interpretation. The microsegregation measurements obtained via the area-scan method are randomly sampled data with instrumental errors. The most widely used for characterizing microsegregation is the F-G method, ${ }^{[50,51]}$ which was used in the current work. However, the cumulative representation of microsegregation data of multicomponent alloys can be misleading since the concentrations for individual elements within the secondary phase alone may produce artificially higher or lower than those in the primary phase. Two new techniques rank sort and WIRS (weighted interval rank sort) for charactering microsegregation in multicomponent alloys were presented by Gansean et al. ${ }^{[60]}$ that are capable of separating the effects of scatter in the data from the underlying segregation trends, assigning each measurement location a unique fraction solid. In comparison to the F-G method, the WIRS approach yields significantly improved estimations of segregation parameters for a series of multicomponent Ni-base superalloys. Mirković et al. ${ }^{[58,61]}$ also applied the WIRS approach for the microsegregation characterizations of AZ31 and AM 50 alloys and confirmed the WIRS scheme is physically reasonable to exploit all the information in the dataset especially for multicomponent alloys. Since the alloys investigated in our current work are only binary $(\mathrm{Mg}-\mathrm{Al})$ and ternary (Mg-Al-Ca, Mg-Al-Sn) alloys and the composition tendency for each alloying element within both the primary and the secondary phases are the same, there is no significant difference for the microsegregation data characterized by the F-G method or the WIRS approach. While the WIRS approach is preferable for charactering microsegregation data since it is applicable to the multicomponent alloys and requires no operator judgment.

\section{Summary}

In this work, a similar numerical micro-model as developed by $\mathrm{Yan}^{[37]}$ was implemented and improved in the PanSolidification module by incorporating back diffusion within the solidified primary phase, as well as the undercooling and dendrite arm coarsening during solidification. Solidification simulations were carried out on a series of $\mathrm{Mg}$ alloys (Mg-Al, Mg-Al-Ca, Mg-Al-Sn) under various cooling rates $(0.12 \sim 150 \mathrm{~K} / \mathrm{s})$ using the same set of kinetic parameters derived from the $\mathrm{Mg}-4 \mathrm{Al}$ alloys. The good agreement between the simulated and measured SDAS and solute microsegregation of $\mathrm{Mg}$ alloys demonstrated the extendibility and predictability of the current method, which is critically important for practical applications. As a 
general tool for solidification simulation, the reliability of PanSolidification simulation is highly dependent on the accuracy of the thermodynamic, mobility, and kinetic-parameter databases. The current PanSolidification module enables the virtual experiments on a series of alloys under different solidification conditions. The valuable data obtained from this CALPHAD-based PanSolidification module provide a critical link between casting process simulation to microstructure modeling within the ICME framework for casting design and manufacturing. Additionally, the microsegregation model developed in this study will provide a useful tool for quality control and process optimization of casting components.

Acknowledgments This investigation is a part of research sponsored by the U.S. Department of Energy under Project DE-EE0006450. This paper was prepared as an account of work sponsored by an agency of the United States Government. Neither the United States Government nor any agency thereof, nor any of their employees, makes any warranty, express or implied, or assumes any legal liability or responsibility for the accuracy, completeness, or usefulness of any information, apparatus, product, or process disclosed, or represents that its use would not infringe privately owned rights. Reference herein to any specific commercial product, process, or service by trade name, trademark, manufacturer, or otherwise does not necessarily constitute or imply its endorsement, recommendation, or favoring by the United States Government or any agency thereof. The views and opinions of authors expressed herein do not necessarily state or reflect those of the United States Government or any agency thereof.

\section{References}

1. A.A. Luo, Magnesium Casting Technology for Structural Applications, J. Mag. Alloys, 2013, 1(1), p 2-22

2. F. Pan, M. Yang, and X. Chen, A Review on Casting Magnesium Alloys: Modification of Commercial Alloys and Development of New Alloys, J. Mater. Sci. Technol., 2016, 32, p 1211-1221

3. W.J. Joost and P.E. Krajewski, Towards Magnesium Alloys for High-Volume Automotive Applications, Scripta Mater., 2017, 128, p 107-112

4. M. Esmaily, J.E. Svensson, S. Fajardo, N. Birbilis, G.S. Frankel, S. Virtanen, R. Arrabal, S. Thomas, and L.G. Johansson, Fundamentals and Advances in Magnesium Alloy Corrosion, Prog. Mater Sci., 2017, 89, p 92-193

5. F. Grosselle, F. Bonollo, G. Timelli, A. Tiziani, and E.D. Corte, Correlation Between Microstructure and Mechanical Properties of Al-Si Cast Alloys, Metall. Ital., 2009, 1, p 25-32

6. National Research Council, Committee on Integrated Computational Materials Engineering. Integrated Computational Materials Engineering: A Transformational Discipline for Improved Competitiveness and National Security, ed., National Academic Press, 2008

7. A.A. Luo, Material Design and Development: From Classical Thermodynamics to CALPHAD and ICME Approaches, Calphad, 2015, 50, p 6-22

8. M.C. Flemings, Solidification Processing, McGraw-Hill, New York, 1974

9. W. Kurz and D.J. Fisher, Fundamentals of Solidification, Trans Tech Publications, Switzerland, 1985
10. K.-O. Yu, Modeling for Casting and Solidification Processing, CRC Press, Boca Raton, 2001

11. Y.A. Chang, S.L. Chen, F. Zhang, X.Y. Yan, F.Y. Xie, R. Schmid-Fetzer, and W.A. Oates, Phase Diagram Calculation: Past, Present and Future, Prog. Mater Sci., 2004, 49, p 313-345

12. M. Hillert, Phase Transformations, Materials Park, ASM, 1968, p 181

13. L. Kaufman and H. Bernstein, Computer Calculation of Phase Diagrams, Academic Press, Cambridge, 1970

14. Y.A. Chang, Phase Diagram Calculations in Teaching, Research, and Industry, Metall. Trans. B, 2006, 37B, p 7-39

15. E. Scheil, Remarks on the Crystal Layer Formation, Z. Metallkd., 1942, 34, p 70-72

16. G.H. Gulliver, The Quantitative Effect of Rapid Cooling Upon the Constitution of Binary Alloys, J. Inst. Met., 1913, 9, p 120157

17. J. Guo and M. Samonds, Modeling of Casting and Solidification Processing, Casting Design and Performanceed, ASM International, Russell Township, 2009, p 37-60

18. U.R. Kattner, The CALPHAD Method and Its Role in Material and Process Development, Technol. Met. Mater. Min., 2016, 13(1), p 3-15

19. V.G. Smith, W.A. Tiller, and J.W. Rutter, A Mathematical Analysis of Solute Redistribution During Solidification, Can. J. Phys., 1955, 33(12), p 723-745

20. H.D. Brody and M.C. Flemings, Solute Redistribution During Dendrite Solidification, Trans. Met. Soc. AIME, 1966, 236, p 143150

21. T.W. Clyne and W. Kurz, Solute Redistribution During Solidification with Rapid Solid State Diffusion, Metall. Trans. A, 1981, 12, p 965-971

22. A. Roósz, Z. Gácsi, and E.G. Fuchs, Solute Redistribution During Solidification and Homogenization of Binary Solid Solution, Acta Metall., 1984, 32(10), p 1745-1754

23. I. Ohnaka, Mathematical Analysis of Solute Redistribution During Solidification with Diffusion in Solid Phase, Trans. Iron Steel Inst. Jpn., 1986, 26(12), p 1045-1051

24. J.A. Sarreal and G.J. ABbaschian, The Effect of Solidification Rate on Microsegregation, Metall. Trans. A, 1986, 17(11), p 2063-2073

25. S. Kobayashi, Solute Redistribution During Solidification with Diffusion in Solid Phase: A Theoretical Analysis, J. Cryst. Growth, 1988, 88(1), p 87-96

26. S. Ganesan and D.R. Poirier, Solute Redistribution in Dendritic Solidification with Diffusion in the Solid, J. Cryst. Growth, 1989, 97(3-4), p 851-859

27. C.Y. Wang and C. Beckermann, A Unified Solute Diffusion Model for Columnar and Equiaxed Dendritic Alloy Solidification, Mater. Sci. Eng. A, 1993, 171(1-2), p 199-211

28. C.Y. Wang and C. Beckermann, A Multiphase Solute Diffusion Model for Dendritic Alloy Solidification, Met. Trans. A, 1993, 24, p 2787-2802

29. L. Nastac and D.M. Stefanescu, An Analytical Model for Solute Redistribution During Solidification of Planar, Columnar and Equiaxed Morphology, Metall. Trans., 1993, 24, p 2017-2118

30. M. Hillert, L. Hoglund, and M. Schalin, Role of Back-Diffusion Studied by Computer Simulation, Metall. Mater. Trans. A, 1999, 30(6), p 1635-1641

31. V.R. Voller, A Model of Microsegregation During Binary Alloy Solidification, Int. J. Heat Mass Transf., 2000, 43, p 2047-2052

32. M. Wu, J. Li, A. Ludwig, and A. Kharicha, Modeling DiffusionGoverned Solidification of Ternary Alloys-Part 1: Coupling Solidification Kinetics with Thermodynamics, Comput. Mater. Sci., 2013, 79, p 830-840

33. T. Kraft, M. Rettenmayr, and H.E. Exner, An Extended Numerical Procedure for Predicting Microstructure and 
Microsegregation of Multicomponent Alloys, Modell. Simul. Mater. Sci. Eng., 1996, 4(2), p 161-177

34. T. Kraft, A. Roósz, and M. Rettenmayr, Undercooling Effects in Microsegregation Modelling, Scripta Mater., 1996, 35, p 77-82

35. T. Kraft and Y.A. Chang, Predicting Microstructure and Microsegregation in Multicomponent Alloys, JOM, 1997, 49(12), p 20-28

36. F.Y. Xie, T. Kraft, Y. Zuo, C.H. Moon, and Y.A. Chang, Microstructure and Microsegregation in Al-rich $\mathrm{Al}-\mathrm{Cu}-\mathrm{Mg}$ Alloys, Acta Mater., 1999, 47(2), p 489-500

37. X. Yan, Thermodynamic and Solidification Modeling Coupled with Experimental Investigation of the Multicomponent Aluminum Alloys, University of Wisconsin-Madison, Madison, 2001

38. W. Cao, S.-L. Chen, F. Zhang, K. Wu, Y. Yang, Y.A. Chang, R. Schmid-Fetzer, and W.A. Oates, PANDAT Software with PanEngine, PanOptimizer and PanPrecipitation for Multi-component Phase Diagram Calculation and Materials Property Simulation, Calphad, 2009, 33(2), p 328-342

39. Pandat ${ }^{\mathrm{TM}}$, Thermodynamic Calculations and Kinetic Simulations, CompuTherm LLC

40. J.H. Perepezko and M. Uttormark, Undercooling and nucleation during solidification, ISIJ Int., 1995, 35(6), p 580-588

41. K. Eckler, D.M. Herlach, and M.J. Aziz, Search for a Solute-Drag Effect in Dendritic Solidification, Acta Metall. Mater., 1994, 42(3), p 975-979

42. W.J. Boettinger and S.R. Coriell, Microstructure Formation in Rapidly Solidified Alloys, Science and Technology of the Undercooled Melted, P.R. Sahm, H. Jones, and C.M. Adam, Ed., Martinus Nijhoff Publisher, Leiden, 1986, p 81-108

43. M.J. Aziz and T. Kaplan, Continuous Growth Model for Interface Motion During Alloy Solidification, Acta Metall., 1988, 36(8), p 2335-2347

44. M. Carrard, M. Gremaud, M. Zimmermann, and W. Kurz, About the Banded Structure in Rapidly Solidified Dendritic and Eutectic Alloys, Acta Metall. Mater., 1992, 40(5), p 983-996

45. T.F. Bower, H.D. Brody, and M.C. Flemings, Measurements of Solute Redistribution in Dendritic Solidification, Trans. Metall. Soc. AIME, 1966, 236, p 624-634

46. R. Trivedi and K. Somboonsuk, Constrained Dendritic Growth and Spacing, Mater. Sci. Eng. A, 1984, 65(1), p 65-74

47. K. Somboonsuk, J.T. Mason, and R. Trivedi, Interdendritic Spacing: Part I. Experimental Studies, Metall Trans A, 1984, 15, p 967-975

48. A. Roósz, E. Halder, and H.E. Exner, Numerical Calculation of Microsegregation in Coarsened Dendritic Microstructures, Mater. Sci. Technol., 1986, 2(11), p 1149-1155
49. A. Roósz and H.E. Exner, Numerical Modelling of Dendritic Solidification in Aluminium-rich Al-Cu-Mg Alloys, Acta Metall. Mater., 1990, 38(2), p 375-380

50. M.C. Flemings, D.R. Poirier, R.V. Barone, and H.D. Brody, Microsegregation in Iron Base Alloys, J. Iron Steel Inst., 1970, 208, p 371-381

51. M.N. Gungor, A Statistically Significant Experimental Technique for Investigating Microsegregation in Cast Alloys, Metall. Trans. A, 1989, 20(11), p 2529-2533

52. M. Paliwal and I.-H. Jung, The Evolution of the Growth Morphology in Mg-Al Alloys Depending on the Cooling rate During Solidification, Acta Mater., 2013, 61(13), p 4848-4860

53. M. Paliwal, Microstructural Development in Mg Alloys During Solidification: An Experimental and Modeling Study, McGill University, Montreal, 2013

54. M. Paliwal and I.-H. Jung, Solid/Liquid Interfacial Energy of MgAl Alloys, Metall. Mater. Trans. A, 2013, 44, p 1636-1640

55. C. Zhang, D. Ma, K.-S. Wu, H.-B. Cao, G.-P. Cao, S. Kou, Y.A. Chang, and X.-Y. Yan, Microstructure and Microsegregation in Directionally Solidified Mg-4Al Alloy, Intermetallics, 2007, 15(10), p 1395-1400

56. X.W. Zheng, A.A. Luo, C. Zhang, J. Dong, and R.A. Waldo, Directional Solidification and Microsegregation in a MagnesiumAluminum-Calcium Alloy, Metall. Mater. Trans. A, 2012, 43(9), p 3239-3248

57. G. Neumann and C. Tuijn, Self-diffusion and Impurity Diffusion in Pure Metals: Handbook of Experimental Data, Elsevier, Amsterdam, 2009

58. D. Mirković and R. Schmid-Fetzer, Directional Solidification of Mg-Al Alloys and Microsegregation Study of Mg Alloys AZ31 and AM50: part I. Methodology, Metall. Mater. Trans. A, 2009, 40, p 958-973

59. J. Lacaze, P. Benigni, and A. Howe, Some Issues Concerning Experiments and Models for Alloy Microsegregation, Adv. Eng. Mater., 2003, 5(1-2), p 37-46

60. M. Ganesan, D. Dye, and P.D. Lee, A Technique for Characterizing Microsegregation in Multicomponent Alloys and Its Application to Single-Crystal Superalloy Castings, Metall. Mater. Trans. A, 2005, 36(8), p 2191-2204

61. D. Mirković and R. Schmid-Fetzer, Directional Solidification of Mg-Al Alloys and Microsegregation Study of Mg Alloys AZ31 and AM50: part II: Comparison between AZ31 and AM50, Metall. Mater. Trans. A, 2009, 40, p 974-981

Publisher's Note Springer Nature remains neutral with regard to jurisdictional claims in published maps and institutional affiliations. 